\title{
The Art of Re-Interpreting Self: Self Imagery in the Works of Indian Artists
}

\author{
Nazima Rangwala Kalita a,1,* \\ a Association for Scientific Computing Electronics and Engineering (ASCEE), ASCEE Visual and Performing Arts Society, India Section., India \\ 1 nazkalita@yahoo.co.in \\ * corresponding author
}

ARTICLE INFO

Article history

Received 2019-09-28

Revised 2019-11-28

Accepted 2019-11-30

Keywords

Self - Imagery

Re-interpretation

Identity

Painting

Performing Art

\section{ABSTRACT}

This study is combining, connecting, or involving many different kinds of artistic disciplines, re-interpreting the event of a self as a new sense of autonomy, and a more modern understanding of individuation. This study aims to examine the knowledge of self-imagery in Indian art through various media and representational techniques of Indian artists' works. Here I will talk about Indian art scenarios in different spaces and times and how Indian artists are affected and how ideas about Self image emerge. The data used in this study are literature data, video of artists' performances, and data on artworks. All data is observed, and the results are separated based on data trends. Separation of information is done by arranging three main variables, namely the background of the life of the artist, the journey of the creation of the work, and the achievements of the artist's work. Observation steps targeting three artists and their actions in India, such as Bhupen Khakhar, Sonia Khurana, and Ranbir Kaleka, further analyzed by referring to the framework of "The Art of Re-Interpreting Self." The result of the study is. Firstly, the artworks of these artists have created different activity sites, meant for shared interaction. Secondly, these artists have used art in a variety of methods to develop and establish representational models involved in social relations. Thirdly, we can see the different roles the artworks of these artists have played as societal capital, identifying individuals in society through access to artwork, or shared forms of knowledge.

This is an open-access article under the CC-BY-SA license.

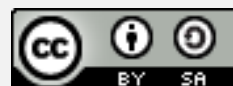

\section{Introduction}

In the modern ages, social representation has been widely deemed by its hypsographic and sociological aspects, i.e., the evolution of types and conventions of image. The relation between human beings, society, and the moral or spiritual attributes that self-image reflect and record figure painting have always constituted an essential ground for the representation of the body as an expression of social norms. In any given period, it represents the existing society by conforming to the expectations of the community, in the setting, poses, attributes, and physical characteristics. The appearance of self-image in the Renaissance of Europe is a big step in the development of representation and also towards the discovering of an individual. The Flemish and Italian paintings embark on the culmination in terms of cod and history of thinking. In the early renaissance of Italy, we come across a complete emphasis on human beings becoming more aware of them. As we can see in the works of Jan van Eyck, The Arnolfini Portrait (1434) [1]. The two figures stand in a small room with a bed, window, and behind the newlyweds, a small round mirror on the wall, showing two individuals entering the room and the formality of the pose illustrated by the man's raised hand in the mirror. The complex symbolism about the painting is that we can see the Van Eyck's unusual 
form of signature: 'Jan van Eyck was here.' Raphael, The School of Athens (1509-11) [2], Raphael 's famous fresco, painted on the wall of the Vatican's Apostolic Palace, is considered a masterpiece of Classicism. The mural symbolizes the marriage of art, philosophy, and science, where we can see his contemporaries in the scene as the philosophers. Plato stands at the left, pointing his finger to the sky. Beside him is his student Aristotle, in a display of superb foreshortening with his right arm directly out toward the viewer. Raphael does not arm all his characters with attributes that give away their identity. Fortunately, there are quite a few that scholars can agree on like Bramante, Euclid, or Archimedes; Michelangelo may be the face of Heraclitus. We can also see Raphael's curious face peeking out from behind the arch on the far right of the fresco.

Michelangelo painted The Last Judgment, ca. (1536-41) on the Sistine Chapel ceiling in the Vatican [3]. In the Last Judgment fresco for the altar wall of the chapel, we can see the insertion of Michelangelo's face on the flayed skin held by St. Bartholomew. The Renaissance master painted his self on the deceased saint, who himself is waiting to know if he is bound for hell or heaven, after a tiring trial of faith. Caravaggio, David with the Head of Goliath, (1609-10) [4]. During the last year of his life, he included his self-portrait depicting David presenting the severed head of Goliath. Caravaggio also painted himself in different manners, one of which was Bacchus, the Greek god of wine. So in the works of these four artists of Renaissance human nature and its subjective spirit and power of expression of compositions were present whether to exhibit an elevated status, to depict technical skills, or an attempt to achieve honest self-reflection. We can also take into note the fact of symbolic portraits in the high renaissance of Germany like Lucas Ganache, Albert Durer, and Holland, which are still unrivaled for their adaptation of human form into the exciting world of painting, were done around the same time.

The aid of costumes and attributes plays an important role. It becomes convenient to describe who is being portrayed precisely. Mannerism is the name of the modern lines that started showing the transience in the existence of human beings. Absolutism, which citizens tried hard to achieve, also resulted in a vast array of portraits between the Sixteenth and eighteenth-century artists like Rembrandt and Frans Hals. The last two centuries have concentrated on finding solutions to actual questions related to psychology and connectivity. In the mid-twentieth century, paintings were corroded off their rights by technology, which has put at your convenience a stack of possibilities, wherein, on the one hand, non-referential art was mandatory, and in other sections, images were acceptable only in readymade form. Throughout centuries, Art has been the redeeming feature of a society that genuinely reflects its role aspirations. In art, self-image has become an essential domain in representing the body as an expression of social norms. Self-imagery offers a venue for discovering the artist's inner self, which plays a broadened role in understanding what this "self" is all about. The question at this moment asked is whether the person is evolved from instincts. It is a complicated question. Just as life cannot be generated by matter, in an atom all by itself, there is a tendency to preserve itself. However, it is determined from within, without any external forces. In an organism, there is life, which is autonomous. Life is self-adoring and assimilates matter into itself. External forces determine it. However, it counteracts the hostile effects of nature. It partly determines its activity. It is self-active, but not conscious. The animal is aware; it feels but does not think. It is not mindful of its end. It has no unity of self. It is a creature of instincts and impulses. It has no reason and self-consciousness. However, man is self-conscious and self-determined.

In the last few years, the rapid growth of technology and related commercial aspirations, and the social and economic implications of globalization have transformed India. The challenge of interpreting themes of collusion where people, places, times, and characters from folklore and myth inhabit many crisscrossing, intersecting, and disconnected maps, to play a role on the global stage [5]. This study aims to examine the understanding of self-imagery in Indian art through various media and representational techniques of Indian artists' works. Here I will talk about Indian art scenarios in different spaces and times and how Indian artists are affected and how ideas about Self image emerge. Besides, as time goes on, technology develops and how perceptions about selfportrayal change with it. The various methods used in this paper aim to address the problem of (1) how self-image in art is used to frame settings; (2) how the art of self-image functions as a space for participation (3) the art of self-image as a representational model for social relations. So, the entire modern Indian art scenario, which ostensibly invites a meticulous inspection of the ongoing art practices, is the motivation for this study, questioning at the same time that whether contemporary Indian Artists are using a multitude of media in their works in order to express themselves or just 
blindly following the west without any honest self intuition? Satyajit Ray spoke of the most disquieting thing that had struck her in many contemporary artists (in India) was their conscious or unconscious ambivalence towards the Indian scene [6]. Too many were either led to escape its powerful challenge through a decorative interpretation of the cultural pattern or else grappled with its realities by espousing primarily western forms and attitudes [7]. Self-imagery in contemporary art is a desired cross-cultural representation of the body that has been passed on throughout the history of human civilization [8]. The study by taking the focus of artwork on three Indian artists, Bhupen Khakhar, Sonia Khurana, and Ranbir Kaleka, is based on the reason that their work is quite prominent. The ideas of these artists which are personal and representative of the transformations taking place globally. These artists traverse the complicated road between the present and the historical past, the fact and fiction, and new and old identities during a public and societal flux [9]. I want to connect their artwork and sincere search for the inner self and how freely they organize themselves in their artwork.

\section{Method}

The data used in this study are literature data, video of artists' performances, and data on artworks. All data is observed, and the results are separated based on data trends. Separation of information is done by arranging three main variables, namely the background of the life of the artist, the journey of the creation of the work, and the achievements of the artist's work. Observation steps targeting three artists and their actions in India, such as Bhupen Khakhar, Sonia Khurana, and Ranbir Kaleka, were further analyzed by referring to the framework of "The Art of Re-Interpreting Self." This observational method is used to test the understanding of self-concept in Indian art through various media and techniques of representation of Indian artists' works. It is hoped that this method can address the problems raised in this study.

\section{Results and Discussion}

\subsection{Idea, Creativity, and Re-Interpretation of Re-Interpreting Self in Paintings of Bhupen Khakhar}

Bhupen khakhra's view of the world is personal instead of that objective. In his view, sexuality swings from possession, alienation, and recapitalization. He tries to rehabilitate the singing protagonist while claiming for normalcy. He reclaims his place in the material and spiritual universe. In the age of technological revolution where images and its adaptation are at our easy disposal, his expression stays highly personal because of his healthy priorities of likes and dislikes. He recreates the link between Indian and contemporary western art [10]. Born on 10th March 1934, he was the youngest of four children. Parmanand, his father, owned a small cloth store. He drank heavily and passed away when Khakhar was just four years old [11]. Then he was taken care of by one of his elder sisters. His mother, Mahalakshmi, the daughter of a school teacher, was a very dominant person in the family. Khakhar's native place was a Portuguese colony in Daman-Gujarat, where they were artisans. They spoke Gujarati at home and also had fluency in Marathi and Hindi [12]. Decidedly less of English with the culmination of three different languages and two different cultures, a hybrid culture of its own evolved at their home. In the early short stories he wrote, it is this same hybrid language that he used since then. He strived to achieve pictorial communication, which would equal his lingual capabilities [13].

As a child, he suffered from an illness that forced him to stay in bed, not going to school. He spent time in abstract musings and creative imagination. Right from the beginning, he was sensitive, idealistic, and vulnerable. Though at school, he secured good marks, his preoccupations were something else. Later he took up chartered accountancy and practical it until the age of twenty-eight. The "New Artis" of friends in Mumbai, who were from Art literature and philosophy background, encouraged him to take up Art seriously. It was then that he moved to Baroda to practice Art, the place of his birth. Baroda at that time was an essential place for New art in India, which gave rise to a new generation of artists like Gulam Mohammed Shaikh, Jyothi Bhatt, Nagji Patel, Jeram Patel, Nasreen Mohamedi and many more [14]. Here he found a very active atmosphere to work. His 
interaction with the English artist Jim Donovan in Baroda was vital in understanding the different western Art trends. He painted people at Dharamshala in 1966. With this printing began his socalled "Neo Miniature" genre of paintings [15]. He preferred to paint portraits of people whom he liked or knew. The first significant group of paintings he produced in 1972, like "Barbershop" (1972), "Janata Watch Repairing" (1972), "Factory Strike" (1972) and "Assistant Accountant Mr. I.M. Shah" (1972), in which he depicted ordinary people from everyday situations and focused on the protagonist of the elite - of Art World [16]. These works were displayed at Triennial. Most of the portraits have highly narrative aspects to them. Pictorially they are divided into a central image of a protagonist who acquires an epic sentiment, and behind him are fictional figures indulged in mundane activities, like in "Man with Bouquet of Plastic Flowers" (1976) and "Man in Pub" (1980) [16].

He successfully analyzes the monotony of everyday life. Here his inheritor is to reconstruct a whole world of specific situations, which are neither satire nor a social comment. While doing these highly narrative paintings, he was very well aware of the debates of Avant-garde. Among the several things that influenced him were medieval illuminated manuscripts by The Siena School works by Brueghel Mantegna, David Hockney, Bonard, and, most of all, the re-examined Indian tradition. Though his images are incredibly personal, they are reminiscent of different European masters like Bruegel, Mantegna, and also exponents of Persian and oriental traditions. During the 1970s, Khakhar traveled extensively to places like the Soviet Union, Italy, and Britain. Here he got the firsthand experience of many original works of art from Russian icons and Italian frescos and also the effective functioning of the London art scene. His idea of exploring narrative possibilities further got enhanced. On the whole, in his earlier period, man's relation to his environment recurs as the prevalent subject matter. They represent the ordinary man; his momentary frustrations and transitional thoughts were very well captured. He could easily empathize with the half-educated urban middle class. There is an immediate identification with them, which fluctuates at different levels [17]. In 1979 he went to England on an invitation to the Bath Academy of Arts to teach there for six months. He stayed at Howard Haskins's place. Many things intrigued him there. He found an environment where homosexuality was accepted in the society without making it a taboo when he returned to India; he openly took his homosexuality, which had remained hidden for a long item in his life. This is probably a very crucial thing, which happened to his life and his painting cover. After his "coming out," homosexuality becomes his central theme; around the same time, he loses his mother. His attachment to Vallav Bhai increases. His new acceptance brings remarkable changes in his art. It becomes genuinely confessional [17]. In the next genre of paintings that he painted, he juxtaposes the self with the world, the individual, and the society the relation between the two becomes interrogatory. In his "You Cannot Please All" (1981) [18] in Figure 1, Khakhar portrays himself nude, in a balcony against a landscape fully inhibited by men. In doing so, he shows his vulnerability precisely - isolated a part of a complex social society yet. "Khakhar, while speaking of this painting, had said, rather naughtily that if needed, one cannot please all, one should please themselves [18].

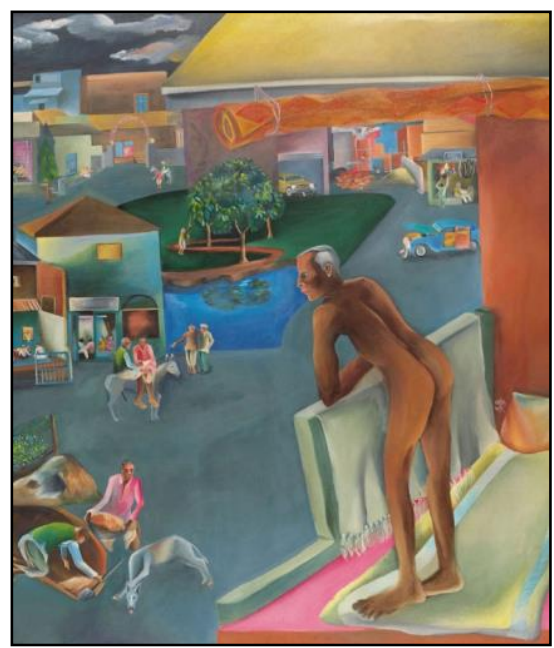

Fig. 1. In his "You Cannot Please All” 1981 - Khakhar Portrays Himself Nude, in a Balcony 
It was after a stint in London that Khakhar started speaking openly about his sexuality, reflecting on the comparative sexual freedoms of the old metropole [19]. His gay sexuality further enabled him to fully enquire into the quests of the "identity of the self." He portrays himself many-a-times in intimate situations with other men, regardless of the state of affairs, as seen in his "Two Men in Benares (1982) [20]. Other mundane lacquers and happenings usually surround the main characters. Through intimacy, the incidents are revealed very fluently. He had a loss of vitality when he reached the age of fifty there, which was a type of self-realization of aging, and from this point onward, his works become a fantasy. In entering the domain of private imagination, he further acquires evergreater social importance. His nude figure of men, like in "ghost city night," set in a green landscape, in which the beat represents the contradiction that exists in modern Indian society [10]. $\mathrm{He}$ has an intelligent manner of wearing the emotional complexities of an individual with that of a larger domain of standards created by the community. Most importantly, Khakhar has been branded India's first openly gay artist, a fact that came to penetrate the images he produced throughout the 1980s and 90s that depicted men among men caught in various lewd acts of sexual union. Khakhar's perceptions of men among men are singular in the context of modernist art practice in India [21].

Self Image is the space where he makes a bold, brave intervention in favor of a pragmatic truce with everyday life and the norms of social relationships, which he translates, quite uniquely, into forms of myriad companionship. This is, in an ultimate eccentricity, his 'experiment with truth' held in place by the singular, irrepressible, act of painting. According to Bhupen Khakhar, art needs to move away from the abstract and aim to represent the familiar milieu or the inhabited locale. Similarly, in his short story Maganbhai's Glue and his play Maujila Manilal, he deliberately places into focus the 'common man' as hero/protagonist and thereby carries on the demystification process that began with his paintings [22]. Most of the portraits of Bhupen Khakhar are painted in his typical township carry an unmistakable semblance to the artist himself, his enormous ears, and straight white hairs. The groups of gathering men from different religious, who keep lounging around, always seem to be waiting for something to happen. There is an air of expectation. The range of colors he chooses is very unreal and nocturnal, giving his works a high tuned visionary quality. Perhaps his most intriguing carry of portraits were those that he did in the 90s. In 1999 he was affected by cancer, during the time which he had to stay in a hospital in Mumbai for several days. There he saw people tainted with wounds, illness, and physical deformity, who were experiencing surgery and human intervention like radiation therapy and radical surgery. He painted several individuals whom he had encountered there, all of which were shown in an exhibition titled "Beauty is Skin Deep Only" (1999) in 2001 at Baroda. Among these portraits, the labyrinth of his typical town is absent and its members like the barber, neighbor, etc., none are present. Here, he attempts huge size portraits, which has been rarely attempted by an Indian artist, concerning such a subject matter.

There are sure fascinating signs which appear on the surface and were involved; ugly narrative iconographic fields, which remain ambiguous for the viewer to interpret. "Bullet Shot in Stomach" (2000), "Manilal with Measles" (2002), and "Injured Head of Raju" (2002); in all these paintings, he uses the pigment itself in a literal sense to show metaphorical analogs of body wounds. These images depict blood clots. It seems like some arrogant pride that artists throughout history have tried to match with painting the grisly wonders of nature. The year 1999 marks another phase in his work. Khakhar's imagery is now oozing blood and entrails. There is a fascination among painters (from Goya to Gericault, from the early expressionists to Francis Bacon) for a menacing form of mortality, the different aspects of human existence, and the blinding darkness of actual death [23], "Bhupen Khakhar" by Geeta Kapur. Death came so abruptly to Bhupen; he addressed it in many ways - with fury, pleas for compassion, with blatant terror. He confirmed that disease ignites desire. His "late style" releases images emotionally invested in the figure of death, yet endowed with such erotic power, a contrarian effect is produced: sublimation and refusal, equally uncompromised [24].

\subsection{Idea, Creativity, and Re-interpretation of Representing Self in Performing Art by Sonia Khurana}

Performing art is a unique form of art where the artist uses their voices and bodies to convey messages presented live to an audience. Performance is a very recent development in visual arts, still developing its vocabulary and grammar to define art through voices and bodies as a medium of art practices [25]. In the 1970s, feminism, shattering taboos regarding the female body, produced revolutionary work through performance art. This led to the extensive history of shaping the "base" 
material of one's own body to create art, taking a definite turn. Regarding self-subjectivity, collection, and desire, outside the understandings of metaphysics, outside the laws of beauty received and renewed in the aesthetics of the West, outside the rigid definitions of gender, female performance is out on a limb, beyond the typical feeblish/reification argument. The springing into the theatrical effect of the female body, the material object of denial, desire, possession, etc. may be a good reason to believe that the often schematized "return of the repressed" is at stake.

To put it another way, the female, as masquerade, is played out as a game penetrated by inputs from the transvestite/transgender bodies, the performative presence of who "denaturalizes" the criteria that determine the gender-sex equation. These enactments make graphic assertions for a transactional economy of gender signs to evaluate embodiments whose existential status is as materially affective as it is discursive, as gracefully polymorphous as it is provocative. A spiritual agency, if such a possibility even exists, is signaled via a repeating, looping masquerade, and when we look at the body of "Sonia," we can easily observe the process of its development and identify it holds as an urban/metropolitan middle-class neighborhood body. Once the identification is made, the process of objectification starts. The art of today is not merely shown. It begs to put on a show and to solicit the participation of the audience. Action paintings invite the engagement of the spectator in the creative act of the artist. The artist-actor appears along with the active art. In happenings, sculptors and painters construct props, create scenes and perform [26]. Sonia Khurana is part of a lineage of women who work through the body, into an erotic efflorescent space, recognized and shown to be thwarted, problematized, blocked, and thus won, by primitive forms of selfexposure.

Sonia Khruana's performance video "Bird-Video Stills" (1999), Figure 2 is part hysterical, part 'irrelevant,' and part abject. The naked body of the artist alights on a pedestal, then tries to take flight, but loses footing. It is a pronunciation of unbelonging, and a declaration of the post-colonial identity, in opposition to Modernism's authority, especially the tradition of its sculpture, and the use of the pedestal.

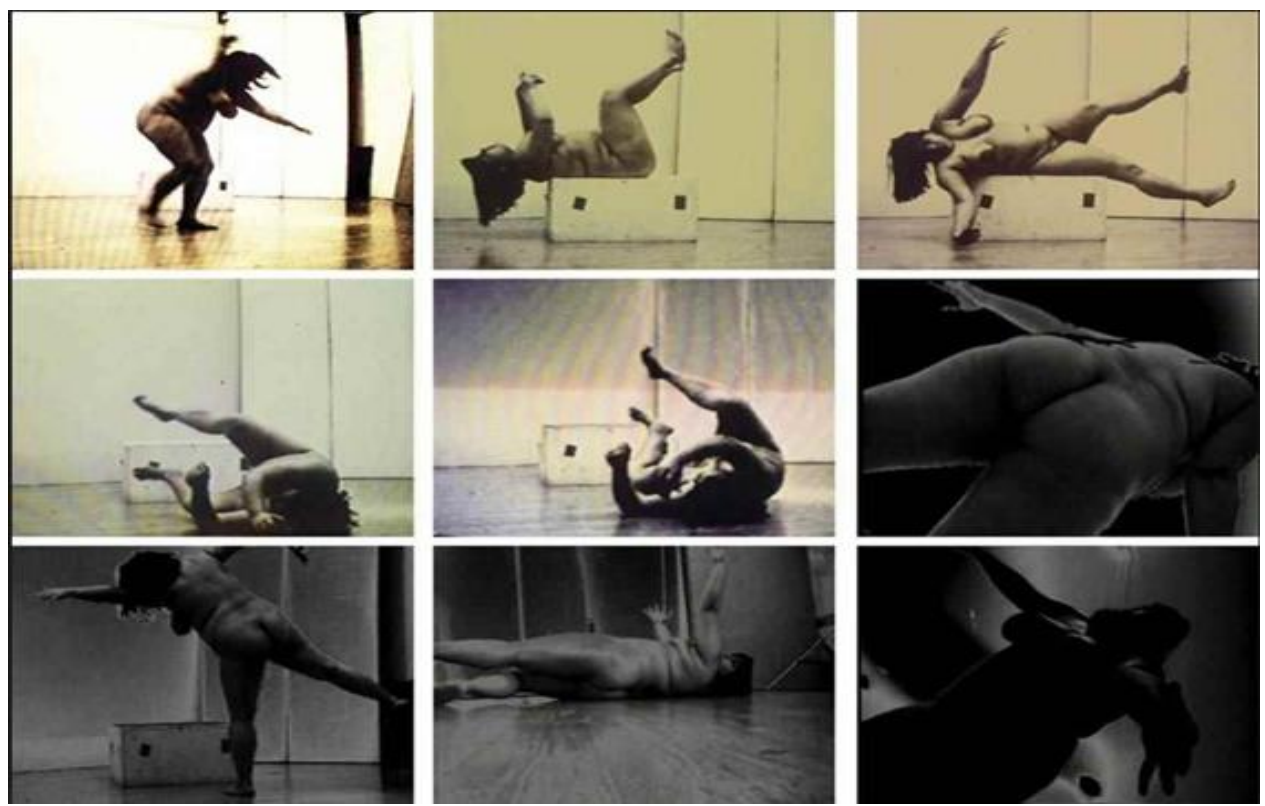

Fig. 2. "Bird-Video Stills", by Sonia Khurana - 1999

In the artwork, the artist can be seen as a dancer, awkwardly naked. She can be seen rolling, jumping, beating her arms, and then trying to take off, grasping the camera, holding it near her flesh. She fails to fly as a dancer, but as an artist, by regulating the velocity, editing the choreography into a fragmented, ballistic parody, she succeeds. The short white and black video, through teasing travesty of formulaic autonomy, provides a kind of autobiographical trace of self-propelled liberation. "Bird" is satirical for being embarrassing, yet it being so classically sublime, it is conflictingly iconic. Here the notion of Self deals with inferiority and embodiment, here the self is about the world. 
The work of Sonia Khruana is well described to internalize experiences and exploration of the world, almost like a ritual specifically by focusing on these gestures as an activist. By placing, the body as an awareness of Transforming the Myth, Subverting the Icon, Issues of Identity, Memory, and Loss, and Healing and Empowerment more so than Global Feminisms [27]. Her practice deals with the self with the world, interiority, and embodiment. Working with a dialogue of power, deliberately peripheral and erratic, she tries to critically draw on the references to the psycho-social domain, the gendered and cultural identity. She tries to explore and redefine the political space through deliberately poetic intimations [28]. In all such actions, the self is already dismantled, not only through metaphorical, literal stripping but also through a contemporary dialogue around belonging and unbelonging. Sonia Khurana is where her interest in blotting out an overly determined feminist dialogue on body emerges, her discomfort with the scoped reign the camera always puts in place. The inquiries, questions she brings to her works, function as a stimulus for the audience to complicate a definition for "the body," the materiality, and to precisely question the meaning of a conscious, aware body.

Khurana interrogates and dis-members the Eurocentric gaze of the body through references to high Modernists castes such as Brancusi, only to reassemble specific fragments and highlight the interwoven nature of the self and other. In doing so, Khurana traces the trajectory of the body throughout history and decenters the Eurocentric gaze to foreground alternative subjectivities. Her increasing interest in the tutoring of the social, deconstructed into partnerships, into communities where the questions of sex, of gender, of identity, can be asked again, alongside others, which require new explanative skills, to negotiate what is now being called, the transcultural transactions around the world.

\subsection{Idea, Creativity, and Re-interpretation of Representing Self in Video Installations by Ranbir Kaleka}

We are often asked why there is so little video art/ video installation in India. The answer is not complicated: mediums and genres and styles become "naturalized' languages and yield their semiotic possibilities differently in different locations. They inscribe themselves into the ongoing processes of artists' work when the time is ripe, when the historic moment arrives, when existential, political, and now, not least when technological conditions mature. The question is hard of chronology, and it is of breakthroughs in one's own time and place to cast as under precisely those myths of origins of birth, civilization, creativity - that make for privileged accounts in art history, national and global. The point is to select your vantage point and, via such surplus uses of languages and techniques that are accessible, to construct fantasies, to born in, to make the real work of art stand for the simultaneity of cultures in the growing universe of contemporary meanings.

Through Video Art exposition, artists can reveal their engagement with their life of the image, also dislodge and re-contextualize the haloed status of the image in contemporary art. Video artists prefer to slowly shift in their vocabulary to what, in contradistinction to the model, maybe called idea, concept, object, installation. Making these categories coeval helps unburden the image; it loosens out the spell - a paralyzing nostalgia into which the imagists, claiming ancestral rights over the vast domain of aesthetics, tend to cast themselves. A more democratic relationship between forms broadens the signifying capacity of the artwork. Photographs, models, film, or television not only because architecture is made available to us through these media but because the built object is itself a system of representation. Living in India in Haveli from childhood "Ranbir's experiences of Haveli were also womb-like...! All my sensations became very strong in terms of my relationship with the outside world, I was living in a state of comfort, I always felt that I could investigate more and would never be hurt." Mr. Kaleka further added, "Curiosity about the self and the world" is an integral part of the work of an artist [29].

Ranbir Kaleka can be placed squarely within a set of concerns pursued by Indian artists. The desire to paint fetish objects has always driven Ranbir Kaleka. Some of his earliest images include 'Men smuggling a fabled creature' (Fish Dreaming of its Holy Captors, 1987), 'Djinn creating fire' (Conjurer 1, Making fire, 1985), Kaleka honed a painterly practice of considerable theatricality, for example in his hugely carnivalesque amalgam (Story-Teller, 1995) and Storyteller-2, White Shadows, 2009 where there is eccentric hedonism around sexuality and the act of painting is mythologized by brushing in rainbows of pigment. In his "Man with Bhutta" (1998), one can see the same model which he features in his new painting-video, washed by a flood of glaring light, holding 
corn so tightly in his hand as if it was the broken prayer wheel of a disloyal monk [30]. When Ranbir uses video, he does not intend to do something describable as video art. Cinema has always interested him, becoming the medium of familiarity for him. He knows that meanings can be created through cinematic forms.

Moreover, in this way, he finds a video to be accessible. He uses available tools, yet his interests still are the same. He does not think that using technology in his work, or changing to a new medium has dramatically changed what he has always been interested in. In the collision between the projected and painted interfaces of video painting, Kaleka arrangements are meticulous in resisting a pluralization of image-forms and media.

Ranbir Kaleka's artwork, "Man Threading a Needle" (1999) in Figure 3, is a painting placed on an easel, presented to the viewer in a dark corner of what is apparently the white box of the gallery/museum [30]. The painting is illuminated in the way an old master painting would be, set aside, devoting special attention for it, when it has just been received and immediately becomes the center of attention and pride of the collection.

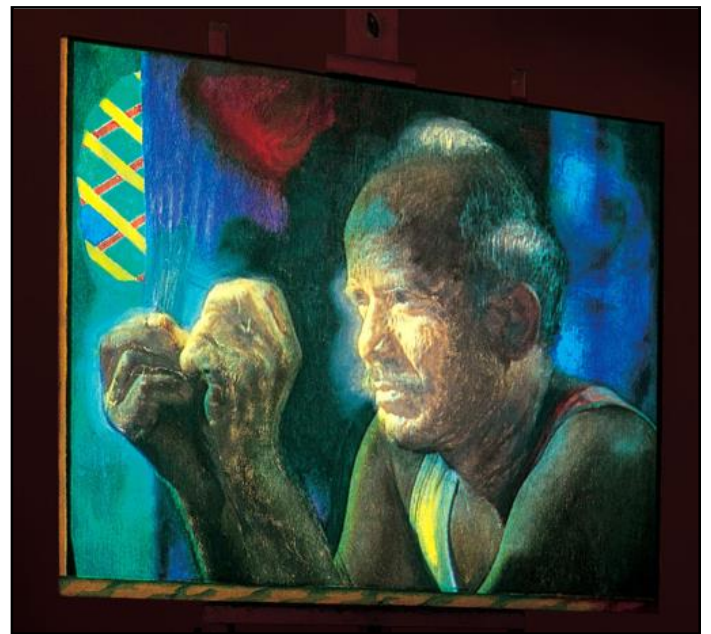

Fig. 3. "Man Threading a Needle" by Ranbir Kaleka - 1999

The viewer enters the area marked by Ranbir, knowing that artwork gets its meaning through the process of seeing it placed in the art gallery, a sacred space. From there on, the creativity and the ingenuity of the artist have to be matched with the viewing etiquette. This combination yields unexpected meanings. A hidden projector provides light. The image twitches now and then, responding to a recurrent audio punctuating and penetrating the image, as it does to the viewer. The viewer slowly realizes that the artist, Ranbir Kaleka, has manipulated the painting, by doubling or rather, tripling its effect by the (video) projection of a real man, onto the painting of the same man. In doing so, he has achieved what must be written into the script for an artist turning to a different visual form. He matches the vision to the image as being in between the video and the painting. Kaleka makes it slightly animate and then presents it as an installation in a professional manner. He brings the near-perversion of its temptations to the surface even as he augments the picture.

Finally, the never-finished nature of Ranbir Kaleka's "Man Threading a Needle," serves as a reminder of the fact that there was, is, and will always be, some struggle at the root of all human lives. The battle is stable in the valiant attempt for success. He presents figures in the video, the interactions, and actions of those who struggle for success. However, not all of his artworks, whether it be a painting or a video, not all of them finish off on a positive note or a resolution [31]. Ranbir's video, "Man Threading a Needle," is still an ongoing process, and the person depicted in it never carries out his task successfully. For some, it may seem defeat, but the man struggling to thread the needle is, in the end, constant, unrelenting and continuous. Perfect fulfillment and success are pathways, and one should continue to make an effort [31]. "Man Threading a Needle" painted and filmed, is a steady, tenacious presence of a (non) performing actor, refusing to leave the stage, virtually instilling himself, shading into the condition of the object that is the due intensification of sound, light and the professional profile. Ranbir Kaleka recognizes the phenomenology of the presence of the object, wherein the artwork palpitates with the encounter. An encounter of the body, unique to the installation, which is neither painting, film, nor theatre. The highly articulate final 
image, almost trompe l'oeil, in the video-painting, has been attained by means artificial, contrived. Each medium's authentic qualities are fuzzed, superimposed, brightened, refocused, then slowed, and jumped up. The image's representational quality is made eerily present, yet less understandable, for all the certainty of the combined means.

Interesting about Ranbir Kaleka's work is that the way he juxtaposes self and his own space by drawing and creating a boundary of how much one transgresses into others' space, or how much one allows everyone to enter the personal area with one's eyes trajectories. With this, he creates a beautiful relation between "self" and "other" in his work of art. Does the Indian notion of "self" vary from more western concepts? Ranbir was told about two gentlemen. These two gentlemen went into this installation, and as they were coming out, they were inquired of as to what they experienced inside the installation. Both of these gentlemen replied that they had perceived their futures. These gentlemen were young, and upon being questioned, they said they saw an older man, his image replacing theirs. There was also a young girl in the pictures that were replaced. Upon inquiry about the girl, the gentlemen said: "Oh, that is our next birth, our afterlife." For these gentlemen, the other was not the other, but rather, they still saw themselves.

Many Indians claim about there being no distinction between what they do or what their experience as art, and other experiences, be they of religious, or of a musical nature. This has proven to be somewhat of a problem, as the term "installation" comes to the Indian scene from the west. We have often been told that all around us we have facilities and those facilities are art. How a vegetable seller sets up his cart, arranging the space around him, is a kind of installation. Not just the vegetable seller, any other person on the street for that matter, is setting up a type of facility. The cow pads, dried up, then made into sculptural forms is also a form of installation, although they sometimes miss out on the fact that there is a conscious generation of meaning in plants, as we now understand in art practice.

Global art emerged from a wide variety of means and materials. These include the recently invented technologies such as the internet, and digital imaging, genres with an extensive past, still being practiced with great passion, such as painting, for example, the works of Nalini Malani [32], and Ranbir Kaleka; and processes and materials that were once primarily associated with handicrafts, are now being re-imagined in order to help the artists express new ideas and concepts. Nowadays, many artists frequently mix media and forms without hesitation, and in doing so, choosing a mixed medium that is best serving their ideas and their purposes. Projects using a mix of media with their primary medium involve projects varying from the spectacular end of the spectrum, projects with huge budgets and stunning production value, to the modest end of the spectrum, with small projects that emphasize the process, the fleeting experiences and a DIY approach. The changes in technology and communications have caused a shift in the notion of influences. All around the world, artists are responding to history, to local geographies, as well as responding to the sway of the visual culture of the whole world. With the global impact, visual culture, as a recognized interdisciplinary field of study, now takes a multifaceted approach in understanding how all types of images communicate and take part in the building of gender, identity, power, relationships, class, and other political and social values and meanings.

Some Indian art critics and artists have now begun conceptualizing their unique position in international contemporary art, questioning modernist ideas of the west, such as formalism from the stance of working in a society that was previously under the shadow of western power, recently emerging and forming a postcolonial society. With theorists such as Gayati Spivak, Homi K. Bhabha, and Arjun Appadurai now developing from India's shore, India has assumed a position at the frontlines of postcolonial critique.

\section{Conclusion}

In this study, these artists worked in a different medium. Still, when it came to the notion of selfimagery in their artwork, the three artists presented themselves very boldly, questioning its existence and brought it to dialogue with the audience. Each of them has presented themselves in a unique style in a different time, bringing out a hidden inner dimension and made it realized through their artworks. In this paper, with the artworks of these three artists, I want to conclude by saying that art is visually affecting, as it is participatory. Firstly, the artworks of these artists have created different 
activity sites, meant for shared interaction and interpretations. Secondly, these artists have used art in a variety of methods to develop and establish representational models involved in social relations. Thirdly, we can see the different roles the artworks of these artists have played as societal capital, identifying individuals in society through access to artwork, or shared forms of knowledge.

\section{References}

[1] E. Panofsky, “Jan van Eyck’s Arnolfini Portrait," Burlingt. Mag. Connoisseurs, vol. 64, no. 372, pp. $117-127,1934$.

[2] W. W. Lloyd, "Raphael's School of Athens," Fine arts Q. Rev., vol. 2, pp. 42-68, 1864.

[3] B. Barnes, Michelangelo's Last Judgment: The Renaissance Response, vol. 5. Univ of California Press, 1998.

[4] M. M. da Caravaggio, "David with the Head of Goliath," Scandal. Vandals, Da Vincis A Gall. Remarkable Art Tales, p. 55, 2007.

[5] B. Fibicher and S. Gopinath, Horn Please: Narratives in Contemporary Indian Art. Hatje Cantz Pub, 2007.

[6] A. Robinson, Satyajit Ray, The Inner Eye: The Biography of a Master Film-Maker. IB Tauris, 2004.

[7] M. Seton, Satyajit Ray: Portrait of a Director. Dobson, 1978.

[8] S. Rapoport and B. L. Williams, "Women, Surrealism and Self-Representation," Leonardo, vol. 32, no. 4, pp. 333-335, 1999.

[9] R. Storer, "Thukral and Tagra," 6th Asia Pacific Trienn. Contemp. Art, p. 174, 2009.

[10] G. Kapur, "Bhupen Khakhar,” Reina Sofia, Madrid, 2002.

[11]R. Verdi, “Old Master Exhibitions,” Burlingt. Mag., vol. 121, no. 917, pp. 536-540, 1979.

[12] R. Vanita and S. Kidwai, Same-Sex Love in India: Readings in Indian Literature. Springer, 2000.

[13]B. Citron, "Bhupen Khakhar's 'Pop' in India, 1970--72," Art J., vol. 71, no. 2, pp. 44-61, 2012.

[14] G. Patel, “Contemporary Indian painting,” Daedalus, vol. 118, no. 4, p. 170, 1989.

[15]P. Jacob, "Worldly Affiliations: Artistic Practice, National Identity, and Modernism in India, 1930-1990. By Sonal Khullar. Oakland: University of California Press, 2015. xiii, 352 pp.," J. Asian Stud., vol. 78, no. 2, pp. 472-474, 2019.

[16]R. Kochhar and others, "Many Facets of an Artist: Collections from The Bhupen Khakhar Estate," Art Asia Pacific, no. 100, p. 159, 2016.

[17]J. Dhar and others, "Bhupen Khakhar: Love in The Time of Bhupen," Art Asia Pacific, no. 98, p. 96, 2016.

[18] S. Mukhopadhyay, "You Can’t Please All: Bhupen Khakhar Retrospective," Museum Worlds, vol. 4, no. 1, p. 233, 2016.

[19] T. Hyman, A. Dodiya, and B. Khakhar, Bhupen Khakhar. Chemould Publications and Arts, 1998.

[20]C. Dercon and N. Raza, Bhupen Khakhar: You Can't Please All. Tate Publishing, 2016.

[21] S. Mukhopadhyay, "Dying Breaths: Bhupen Khakhar, Queerness, and Late Style," UCLA, 2017.

[22] A. Bhatia, "Representations of Street-Life in the Art and Literature of Bhupen Khakhar," Contemp. Lit. Rev. India, vol. 4, no. 4, pp. 23-41, 2017.

[23]G. Kapur, "When Was Modernism: Essays on Contemporary Cultural Practice in India," in Body as Gesture: Women Artists at Work, 2000.

[24] G. Kapur, "Proposition Avant-Garde: A View from the South," Art J., vol. 77, no. 1, pp. 87-89, 2018.

[25]R. Schneider, The Explicit Body in Performance. Routledge, 2013.

[26] P. N. Mago, Contemporary Art in India: A Perspective. National Book Trust, India, 2001. 
[27] M. Reilly, L. Nochlin, B. Museum, D. Museum, and C. Center, Global Feminisms: New Directions in Contemporary Art. Merrell, 2007.

[28] L. Wainwright, "Bodily Relations and Reciprocity in the Art of Sonia Khurana," Cult. Dyn., vol. 29, no. 4, pp. 255-274, 2017.

[29]F. Abrar, "Use of Digital Art in Contemporary Indian Era.," Aligarh Muslim University, 2015.

[30] Turning Poin, "Spectres of the Real," The Art News Magazine of India, vol. 4, no. 3, India, pp. 54-57, 1999.

[31]S. Miller and R. Bellour, "Being Human: Ranbir Kaleka's Latest Works Create Meaning through Painting, Video Projection, Successes and Failures,” 2005.

[32] Nalini Malani, “Some Works of Nalini Malani,” in Arcadja Auction Result, 2019. 